\title{
Olimpíadas de Química Mais e Júnior 2021
}

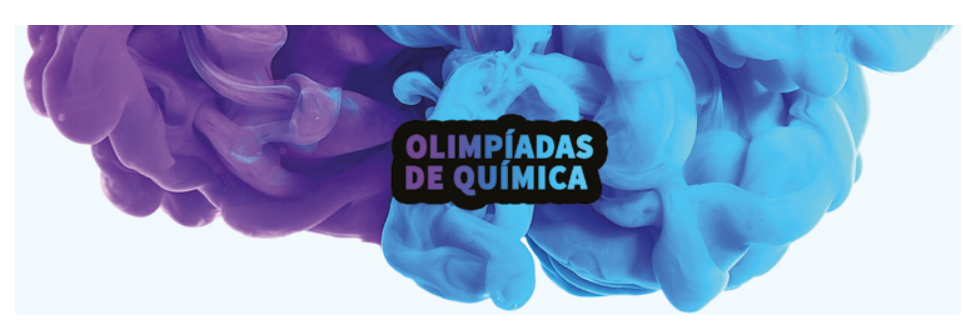

Este ano, mais uma vez em virtude da situação pandémica da COVID-19 que vivemos, todas as atividades das Olimpíadas foram realizadas à distância.

As finais nacionais das Olimpíadas de Química Mais e Júnior foram realizadas no dia 30 de setembro, estando os estudantes em casa, no caso das Mais, e na Escola no caso das Júnior.

As provas foram realizadas na plataforma elearning, sendo todo o processo de preparação das provas e controlo da sua realização feito pelos responsáveis do Departamento de Química da Universidade de Aveiro. A sessão de abertura contou com a presença do Professor Doutor Armando Silvestre, Diretor do Departamento de Química, e do Professor Doutor Artur Silva, Vice-Reitor da UA e Presidente da SPQ.

Os estudantes demonstraram entusiasmo durante a realização da prova e obtiveram excelentes resultados, que implicaram a utilização do tempo gasto na realização da prova para atribuição das medalhas aos primeiros classificados.
Resultados da Final Nacional das Olimpíadas de Química Mais

Ouro: Benedita Ferreira Machado (Colégio Luso-Francês, Porto; Professora Rosana Marques);

Prata: João Afonso Monteiro Tavares (Colégio Pedro Arrupe, Lisboa; Professora Maria João Morgado);

Bronze: Diogo Porto Pires Infante de Oliveira (Colégio Pedro Arrupe, Lisboa; Professora Maria João Morgado);

Diploma de Melhor Escola: Colégio Pedro Arrupe, Lisboa, Professora Maria João Morgado.

Resultados da Final Nacional das Olimpíadas de Química Júnior

Ouro: Leonardo Oliveira, Shaun Kim e Mateus Duarte Gaspar do Nascimento (Escola Salesiana do Estoril; Professora Rita Conde R. Silva);

Prata: Inês Carvalho Costa, Álvaro Gil Azevedo Vieira de Castro e Inês Ferreira Galas (Escola Básica dos 2. ${ }^{\circ}$ e 3. ${ }^{\circ}$ Ciclos de Júlio Brandão, Vila Nova de Famalicão; Professora Maria de Fátima da Silva Ferreira);

Bronze: Afonso Cláudio Machado, Duarte Alexandre Cunha e Silva e José Afonso Ribeiro Santos Silva (Escola Secundária Camilo Castelo Branco, Vila Nova de Famalicão; Professora Ana Maria Gonçalves Portela dos Santos).

$>$

$\begin{array}{lll}\text { Diana Pinto } & \text { João Pereira } & \text { Vasco Batista } \\ \text { diana@ua.pt } & \text { miguel.joao@ua.pt } & \text { vfb@ua.pt }\end{array}$

\section{Uma Medalha de Prata e Duas de Bronze para Portugal nas XXV Olimpíadas Ibero-americanas de Química}

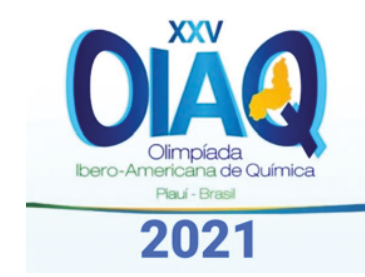

A delegação portuguesa das Olimpíadas Ibero-americanas de Química (OIAQ 2021) completou o ciclo de Olimpíadas no passado dia 9 de outubro de 2021 com premiação plena. Esta delegaç̧ão tinha já participado na 53. a edição das Olimpíadas Internacionais de Química - Japão (ICh0 2021), que decorreu remotamente no passado mês de julho.

João Caldeira, finalista da Escola Secundária Infanta D. Maria (Coimbra), que ganhou uma menção honrosa nas IChO 2021, ganhou a Medalha de Prata. Beatriz Figueiredo, finalista da mesma escola, ganhou a Medalha de Bronze. Mariana Costa, aluna de $11 .^{\circ}$ ano da Escola Secundária Camilo Castelo Branco (Vila
Real), ganhou a Medalha de Bronze. Tiago Sousa, aluno de $10{ }^{\circ}$ ano da Escola Secundária de São João do Estoril, recebeu uma Menção Honrosa. A delegação portuguesa foi ainda composta pelos mentores João M. Pimenta Pereira e Vasco Figueiredo Batista, ambos alunos de Doutoramento no Departamento de Química da Universidade de Aveiro (DQUA).

A Sociedade Portuguesa de Química agradece a colaboração de todos os envolvidos na preparação para as OIAQ 2021, além dos já mencionados: Carlos Silva, Ricardo Santos (alunos do DQUA) e Professores Avelino Freitas, Amparo Faustino e Diana Pinto.

A 25. a edição das OIAQ, sediada na Universidade 